\title{
AVALIAÇÃO IN VITRO DA EFICÁCIA DE EXTRATOS DE PLANTAS MEDICINAIS DO CERRADO FRENTE STAPHYLOCOCCUS AUREUS ISOLADO DE DIFERENTES FONTES DE PROPRIEDADES LEITEIRAS
}

\author{
T.T. Nader ${ }^{1}$, J.S. Coppede ${ }^{2}$, L.A. Amaral ${ }^{1}$, A.L. Facchin ${ }^{2}$, A.M.S. Pereira ${ }^{2}$, L.M. Ferreira ${ }^{1}$ \\ ${ }^{1}$ Universidade Estadual Paulista, Departamento de Medicina Veterinária Preventiva e Reprodução Animal, \\ Prof. Paulo Castellane, s/no , CEP 14884-900, Jaboticabal, SP, Brasil. E-mail: talitanader@hotmail.com
}

\section{RESUMO}

\begin{abstract}
O presente estudo teve como objetivo avaliar o potencial de atividade antimicrobiana in vitro dos extratos de algumas plantas endêmicas do Cerrado tais como Baccharis dracunculifolia, Cochlospermum regium, Croton antisyphiliticus, Eugenia dysenterica e Lippia sidoides, frente ao agente Staphylococcus aureus isolado de leite mastítico, ósteo do teto da vaca, equipamento de ordenhadeira, fossas nasais e garganta do ordenhador. Os extratos foram preparados a partir das partes aéreas e sistema radicular das plantas utilizando os solventes metanol, hexano e clorofórmio na concentração de $10 \%$. Para avaliação da atividade antimicrobiana foi aplicada a técnica de microdiluição em caldo para determinação da Concentração Inibitória Mínima (CIM) seguida da determinação da Concentração Bactericida Mínima (MBC). Os extratos de Baccharis dracunculifolia, Croton antisyphiliticus, seguido do extrato de Lippia sidoides, apresentaram, respectivamente, melhor atividade inibitória sobre a multiplicação da bactéria Staphylococcus aureus. Os resultados obtidos demonstraram, ainda, que as estirpes isoladas do leite e das fossas nasais do ordenhador foram resistentes a gentamicina, princípio ativo muito utilizado no combate à mastite bovina, porém sensíveis aos extratos das plantas referidas, reforçando a importância das plantas medicinais como recurso terapêutico e sua aplicabilidade.
\end{abstract}

PALAVRAS-CHAVE: Atividade antimicrobiana, fitoterapia, Lippia, Baccharis, Croton.

\section{ABSTRACT}

IN-VITRO EVALUATION OF EXTRACT OF MEDICINAL PLANTS FROM CERRADO AGAINST THE STAPHYLOCOCCUS AUREUS ISOLATED FROM DIFFERENT ORIGINS ON DAIRY FARMS. The objective of this study is to evaluate the potencial microbial activity in-vitro from the extract of some endemic plants from Cerrado such as Baccharis dracunculifolia, Cochlospermum regium, Croton antisyphiliticus, Eugenia dysenterica and Lippia sidoides, against the agent Staphylococcus aureus isolated from bovine mastitic milk, osteo from cow's teat, milker equipament, nasal cavitites and milker's gullet. The extracts were prepared from aerial parts as well as the reticular systems of plants using the solvents methanol, hexane and chloroform at a concentration of $10 \%$. To evaluate the antimicrobial activity, the technique of microdilution in broth was used for determining the Minimal Inibitory Concentration (MIC) followed by the determination of Minimal Bactericidal Concentration (MBC). The extracts from Baccharis dracunculifolia and Croton antisyphiliticus, followed by extracts from Lippia sidoides, reported respectively, presented better inhibitory activity against the multiplication of the bacteria Staphylococcus aureus. Furthermore, the results demonstrate that the isolated strains from the milk and nasal cavities of the milker showed strong resistance against gentamicin, active agent commonly applied to combat mastitis bovine. However, there was sensitivity against extracts from the reported plants, reinforcing the importance of the medicinal plants as a therapeutic resource and its aplicability.

KEY WORDS: Antimicrobial activity, phytotherapy, Lippia, Baccharis, Croton.

\section{INTRODUÇÃO}

O leite bovino é um alimento essencial na dieta humana e a qualidade do produto in natura é influenciada diretamentepelasaúdedaglândulamamáriadoanimal, por fatores zootécnicos associados ao manejo, alimentação, potencial genético dos rebanhos e por processos de obtenção e armazenamento do leite (SouzA et al., 2005).

${ }^{2}$ Universidade de Ribeirão Preto, Departamento de Biotecnologia, Ribeirão Preto, SP, Brasil. 
O fator limitante mais relevante na produção leiteira é a ocorrência de mastite bovina, caracterizada por processo inflamatório da glândula mamária, responsável pelas maiores perdas econômicas do setor devido ao comprometimento da produtividade (BALABAN; RAZOOLY, 2000). Em diversos países o principal agente etiológico da mastite bovina é o micro-organismo Staphylococcus aureus (SÁ et al., 2004), o qual desempenha importante papel na epidemiologia de doenças veiculadas por alimentos, pois produz toxinas termorresistentes causadoras de gastroenterites alimentares no ser humano, e ainda possui fatores de virulência que conferem alta resistência aos antimicrobianos (ZECCONI; HAHN, 2000).

A dificuldade no controlee tratamento da mastite, aliada a existência de estudos prévios que relatam a presença de substâncias em plantas nativas com atividade antimicrobiana, torna promissora a pesquisa com extratos e compostos de origem vegetal (RIOS; ReCCIO, 2005; SHER, 2009).

Diante da realidade apresentadajustifica-se o presente estudo, que tem como objetivo avaliar o potencial antimicrobiano de extratos das espécies Baccharis dracunculifolia (vassourinha), Cochlospermum regium (algodãozinho docampo), Crotonantisyphiliticus (péde perdiz), Eugenia dysenterica (cagaita) e Lippia sidoides (alecrim pimenta), endêmicas do Cerrado, frente ao agente etiológico, isolados de leite mastítico, bem como de outras fontes de contaminação envolvidas na cadeia produtiva do leite.

\section{MATERIAL E MÉTODOS}

As espécies alvo desse trabalho foram: L. sidoides (folha), C. regium (casca, entre casca e cerne da raiz), B. dracunculifolia (folha), C. antisyphiliticum (raíz) e E. dysenterica (folha), elas foram herborizadas e receberam os vouchers: HPM 1327, HPM 272, HPM 1334, HPM 293, e HPM 1335, respectivamente.

As plantas foram coletadas no Município de Araxá, MG, próximo à reserva ecológica Ecocerrado Brasil localizada à margem da BR 262, no $\mathrm{km} \mathrm{715,}$

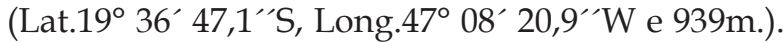
As identificações taxonômicas foram realizadas por especialistas do Instituto de Botânica da USP, São Paulo e as exsicatas foram depositados no herbário da Universidade de Ribeirão Preto (UNAERP). Esse trabalho tem autorização especial de acesso e de remessa de amostra de componentes do patrimônio genético emitido pelo IBAMA (Processo 02001.000466/2009-77).

As partes aéreas e sistema radicular foram secos em estufa com circulação forçada de ar a $50^{\circ} \mathrm{Ce}$, em seguida, pulverizadas em moinho de faca (Marconi ${ }^{\circledR}$ ) atéa obtenção de material com partículas de 40 mesh. Para a preparação dos extratos foram utilizados
$10 \%(\mathrm{P} / \mathrm{V})$ de droga vegetal e os solventes metanol, hexano e clorofórmio. O processo de maceração foi estático, em temperatura ambiente, com homogeneizações diárias por sete dias. Posteriormente, as soluções foram filtradas em papel filtro Whatman $\mathrm{n}^{\circ} 1$ e rotaevaporadas. O processo de obtenção dos extratos foi executado no Laboratório de Fitoquímica do Departamento de Biotecnologia de Plantas Medicinais da UNAERP. Para a realização dos ensaios com os isolados das bactérias, os extratos foram dissolvidos inicialmente em dimetilsulfóxido (DMSO) seguidos da adição de Tween 80 , com concentração final de $10 \mathrm{mg} / \mathrm{mL}$.

As amostras dos micro-organismos foram obtidas por FERREIRA (2008) de uma propriedade rural de exploração leiteira localizada na região nordeste do Estado de São Paulo, na qual foram selecionadas fêmeas que apresentassem sinais clínicos de mastite descritos por Costa et al. (2000), bem como resultado positivo para o California Mastitis Test (CMT). A partir desses animais, amostras de diversas fontes de veiculação da doença foram obtidas de acordo com os procedimentos recomendados pelo National Mastitis Council (HARMON et al., 1990). Os micro-organismos isolados foram gentilmente cedidos pelo Prof. Dr. Antonio Nader Filho, docente do Departamento de Medicina Veterinária Preventiva e Reprodução AnimaldaUNESP -Jaboticabal, ecujosisolamentos foram realizados a partir do desenvolvimento de projeto Auxilio Pesquisa, apoiado pela FAPESP (05/53856-3).

No presente estudo foramutilizadas seis estirpes, isoladas respectivamente do leite mastítico, ósteo do teto da vaca, equipamento de ordenhadeira, fossas nasais e garganta do ordenhador, e uma cepa padrão ATCC 25923. Testes de sensibilidade in vitro frente à gentamicina foram realizados e foram identificadas três estirpes sensíveis e três resistentes (BAUER et al., 1966). A gentamicina foi utilizada como o antibiótico de escolha devido a excelente atividade exercida sobre o $S$. aureus nos casos de mastite tratados no período de lactação, bem como frente a tais micro-organismos isolados do leite de animais enfermos (ZAFALON et al., 2007; NADER FILHO et al., 2007).

Para avaliação da atividade antimicrobiana dos extratos das plantas in vitro foi aplicada a técnica de microdiluição em caldo para determinação da Concentração Inibitória Mínima (CIM), de acordo com a descrição em Clinica AND LABORATORY STANDARDS INSTITUTE (2003). Foi utilizada a gentamicina como antibiótico de referência sobre os isolados de $S$. aureus. A Concentração Bactericida Mínima (CBM) foi determinada segundo SMITH-PALMER (1998) com modificações. O experimento foi realizado no Laboratório de Biologia Molecular do Departamento de Biotecnologia de Plantas Medicinais UNAERP, Estado de São Paulo. 


\section{RESULTADOS E DISCUSSÃO}

Os dados apresentados no presente trabalho mostram que o extrato clorofórmico de $B$. dracunculifolia tem considerável atividade in vitro sobre as estirpes de S. aureus isoladas do teto da vaca, garganta do ordenhador e cepa padrão ATCC, enquanto o extrato metanólico exerceu ação inibitória sobre as cepas de origem humana (fossas nasais e garganta). $\mathrm{O}$ extrato hexânico apresentou CIM de 5\% apenas sobre a estirpe isolada da garganta do ordenhador (Tabela 1). Tais resultados corroboram com os dados obtidos por Silva FilHo et al. (2008). Esses autores avaliaram a atividade antimicrobiana do extrato bruto defolha em diclometano, sobre S. aureus ATCC 43300 e obtiveram concentração inibitória a 50\% e $100 \mu \mathrm{g}$, sendo essa atividade atribuída aos triterpenos ácido ursólico e 2a-hidroxiácido ursólico isolados do extrato. Segundo FERRONATO et al. (2007), substâncias voláteis presentes noóleo essencial de B. dracunculifolia tambémapresentam atividade contra $S$. aureus. Além disso, há relatos na literatura com outras espécies de Baccharis como $B$. trimera (AvANCINI et al., 2000) e B. nitida (RANGEL et al., 2001) mostrando a ação antimicrobiana dessas plantas sobre a mesma bactéria. Esses dados elucidam que o gênero Baccharis bem como espéciedracunculifolia são promissores para o desenvolvimentodemedicamento fitoterápico antimicrobiano e que várias substâncias são responsáveis por essa atividade.

Outra espécie estudada no presente trabalho foi a Cochlospermum regium Mart. denominada popularmente de algodãozinho, pertencente à família Cochlospermaceae. Os extratos hexânico, clorofórmico e metanólico obtidos a partir da casca, da entre casca e do cerne da raiz da planta não inibiram in vitro o crescimento das cepas de $S$. aureus, agente causal da mastite bovina. Esse resultado diverge dos dados obtidos por OliverRa et al. (1996), que demonstraram a atividade do extrato hexanico frente $S$. aureus e $E$. coli com efetividade semelhante ao antibiótico vancomicina e cefoxitina e também dos resultados apresentados por BRUM et al. (1997) que, ao utilizarem o óleo essencial de $C$. regium contra $S$. aureus, determinaram uma CIM de $1.5 \mathrm{mg} / \mathrm{mL}$. Embora levantamentos etnofarmacológicos demostrem sua utilização como antissépticoeminfecções ginecológicas e para tratarúlceras internas e externas (TRESVENZOL et al., 2006; NUNES et al., 2003; SouZA; FelfiLI, 2006), serão necessárias novas pesquisas para assegurar o uso dessa espécie como antimicrobiano, considerando que variações genéticas e ambientais podem estar interferindo nos resultados apresentados. Estudos envolvendo diferentes genótipos coletados em ambientes diversos poderão, nofuturo, explicar as diferençasencontradas nos estudos mencionados acima.

Resultados semelhantes ao obtido com a espécie C. regium foram observados com a planta Eugenia dysenterica DC. (Myrtaceae). Uma importante frutífera nativa do Cerrado, conhecida popularmente como cagaiteira. Nenhum dos extratos avaliados apresentou atividade antimicrobiana in vitro contra $S$. aureus. Entretanto, segundo Costa et al. (2000), o óleo essencial extraído das folhas dessa espécie apresentou atividade antifúngica com CIM de $3.12 \mathrm{mg} / \mathrm{mL}$ contra Cryptococcus neoformans var. neoformans e C. neoformans var. gatti.

Tabela 1 - Determinação da Concentração Inibitória Mínima (CIM) dos extratos de plantas medicinais do Cerrado frente a isolados de campo da espécie Staphylococcus aureus, agente causal da mastite bovina.

\begin{tabular}{|c|c|c|c|c|c|c|}
\hline Extrato (Solvente) & Leite & Teto & Ordenhadeira & $\begin{array}{c}\text { Fossas } \\
\text { nasais }\end{array}$ & Garganta & $\begin{array}{l}\text { ATCC } \\
25923\end{array}$ \\
\hline Baccharis dracunculifolia (C) & * & $125 \mu \mathrm{g}$ & * & * & $125 \mu \mathrm{g}$ & $500 \mu \mathrm{g}$ \\
\hline Baccharis dracunculifolia $(\mathrm{H})$ & * & $*$ & * & * & $500 \mu \mathrm{g}$ & * \\
\hline Baccharis dracunculifolia (M) & * & * & * & $125 \mu \mathrm{g}$ & $250 \mu \mathrm{g}$ & * \\
\hline Cochlospermum regium casca (M) & * & * & * & * & * & * \\
\hline Cochlospermum regium entre casca $(\mathrm{H})$ & * & * & * & * & * & * \\
\hline Cochlospermum regium entre casca (M) & * & * & * & * & * & * \\
\hline Cochlospermum regium cerne raíz (C) & * & * & * & * & * & * \\
\hline Cochlospermum regium cerne raíz $(\mathrm{H})$ & * & * & * & * & * & * \\
\hline Cochlospermum regium cerne raíz (M) & * & * & * & * & * & * \\
\hline Croton antisyphiliticus (C) & $125 \mu \mathrm{g}$ & $125 \mu \mathrm{g}$ & * & $250 \mu \mathrm{g}$ & $500 \mu \mathrm{g}$ & $125 \mu \mathrm{g}$ \\
\hline Croton antisyphiliticus $(\mathrm{H})$ & $250 \mu \mathrm{g}$ & $125 \mu \mathrm{g}$ & * & $125 \mu \mathrm{g}$ & $500 \mu \mathrm{g}$ & $125 \mu \mathrm{g}$ \\
\hline Croton antisyphiliticus (M) & $*$ & $* 0$ & * & $*$ & * & $*$ \\
\hline Eugenia dysenterica (M) & * & * & * & * & * & * \\
\hline Lippia sidoides $(\mathrm{H})$ & $500 \mu \mathrm{g}$ & * & * & $500 \mu \mathrm{g}$ & * & * \\
\hline Lippia sidoides (M) & * & * & * & $*$ & * & * \\
\hline Gentamicina $30 \mu \mathrm{g}$ & $\mathrm{R}$ & $S$ & $\mathrm{R}$ & $\mathrm{R}$ & $S$ & $S$ \\
\hline
\end{tabular}

*Concentração inibitória mínima superior a $1 \mathrm{mg}$ ou ação bacteriostática; $\mathrm{C}=$ Clorofórmio; $\mathrm{H}=\mathrm{Hexano;} \mathrm{M}=\mathrm{Metanol}$; $\mathrm{R}=$ Resistente (houve multiplicação bacteriana); $\mathrm{S}=$ Sensível (não houve multiplicação bacteriana). 
O estudo realizado com Croton antisyphiliticus (Euphorbiaceae), uma planta também endêmica do Cerrado, que até o presente momento não foi investigada quanto à atividade biológica e investigações químicas, mostrou que o extrato metanólico não inibiu a multiplicação bacteriana de forma satisfatória, entretanto os extratos clorofórmico e hexânico exerceram expressiva atividade in vitro sobre as estirpes testadas, com exceção da estirpe isolada a partir da ordenhadeira (Tabela 1). A utilização dessa espécie é preconizada por populações tradicionais para tratar úlceras externas e eczemas e o presente trabalho vem contribuir para a comprovação da atividade antimicrobiana sugerida em levantamentos etnofarmacológicos (Rodrigues; CARVAlHo, 2001; Rodrigues et al., 2002; FENNER et al., 2006).

Outra espécie investigada neste trabalho foi a Lippia sidoides Cham. (Verbenaceae) uma planta popularmente conhecida como alecrim-pimenta, endêmica dos biomas Cerrado e Caatinga. Vários estudos têm mostrado a atividade antimicrobiana do óleo de L. sidoides, a qual tem sido atribuída principalmente ao timol e carvacrol, ambas substâncias antissépticas consagradas (Matos; Oliveira, 1998; DUARTE et al., 2005). Trabalhos realizados por BERTINI et al. (2005) e Oliveira et al. (2006) mostraram que o óleo essencial de L. sidoides apresentou sobre cepas de $S$. aureus uma CIM inferior a $5 \%$. No presente estudo o extrato hexânico de L. sidoides apresentou CIM de 5\% sobre as estirpes isoladas do leite e das fossas nasais do ordenhador, já o extrato metanólico não inibiu o crescimento da bactéria. Esse resultado elucida que a planta apresenta compostos não voláteis com ação antimicrobiana, merecendo assim investigações do ponto de vista fitoquímico para a elucidação de estruturas responsáveis por essa atividade.

\section{CONCLUSÃO}

Diante dos resultados observados sob as condições deste estudo, conclui-se que os extratos de B. dracunculifolia, C. antisyphiliticus, seguido de $L$. sidoides, demonstraram melhor atividade inibitória e bactericida in vitro sobre a multiplicação da bactéria $S$. aureus, causadora da mastite bovina. Ressalta-se que as estirpes isoladas diretamente do leite e das fossas nasais do ordenhador apresentaram-se resistentes à gentamicina, porém sensíveis às plantas referidas. Considerando a atual problemática da dificuldade no controle e tratamento da mastite bovina, bem como a presença de resíduos de antibióticos no leite ederivados, os dados obtidos evidenciam o potencial uso das plantas medicinais como recurso terapêutico no controle dessa enfermidade.

\section{REFERENCIAS}

AVANCINI, C.A.M.; WIEST, J.M.; MUNDSTOCK, E. Bacteriostatic and bactericidal activity of the Baccharis trimera (Less.) D.C. - Compositae decocto, as disinfectant or antisseptic. Arquivo Brasileiro de Medicina Veterinária e Zootecnia, v.52, n.3, p.230-234, 2000.

BALABAN, N.; RASOOLY, A. Staphylococcal enterotoxins (review). International Journal of Food Microbiology, v.61, p.1-10, 2000.

BAUER, A.W., KIRB, W.M.M., SHERRIS, J.C. TURCK, M. Antibiotics susceptibility testing by a standardized single disk method. American Journal of Pathology, v.19, p.493-496, 1966.

BERTINI, L.M.; PEREIRA, A.F.; OLIVEIRA, C.L.L. de; MENEZES, E.A.; MORAIS, S.M. de; CUNHA, F.A.; CAVALCANTI, E.S.B. Perfil de sensibilidade de bactérias frente a óleos essenciais de algumas plantas do nordeste do Brasil. Infarma, v.17, n.3/4, p. 80-83, 2005.

BRUM, R.L.; HONDA, N.K.; HESS, S.C.; CRUZ, A.B.; MORETTO, E. Antibacterial activity of Cochlospermum regium essential oil. Fitoterapia, v.68, n.1, p.79, 1997.

COSTA, E.O.; GARINO JÚNIOR, F.; MELVILLE, P.A. Estudo da etiologia das mastites bovinas nas sete principais bacias leiteiras do Estado de São Paulo. Napgama, v.3, n.4, p.6-13, 2000 .

CLINICAL AND LABORATORY STANDARDS INSTITUTE. Methods for dilution antimicrobial susceptibility tests for bacteria that grow aerobically: approved standard M7-A6. 6.ed. Wayne: NCCLS, 2003. (NCCL Documento M7-A6).

DUARTE, M.C.T.; FIGUEIRA, G.M.; SARTORATTO, A.; REHDER, V.L.; DELARMELINA, C. Anti-Candida activity of Brazilian medicinal plants. Journal of Ethnopharmacology, v.97, p.305-311, 2005.

FENNER, R.; BETTI, A.H.; MENTZ, L.A.; RATES, S.M.K. Plantas utilizadas na medicina popular brasileira com potencial atividade antifúngica. Revista Brasileira de Ciências Farmacêuticas, v.42, n.3, p.369-374, 2006.

FERREIRA, L. M. Epidemiologia molecular aplicada ao monitoramento de estirpes de Staphylococcus aureus envolvidas em casos de mastite bovina. 2008. Tese (Doutorado) - Faculdade de Ciências Agrárias e Veterinárias, Universidade Estadual Paulista, Jaboticabal, 2008.

FERRONATO, R.; MARCHESAN, E.D.; PEZENTI, E.; ALENCAR, S. M.; ONOFRE, S. B. Atividade antimicrobiana de óleos essenciais produzidos por Baccharis dracunculifolia D.C. e Baccharis uncinella D.C. (Asteraceae). Revista Brasileira de Farmacognosia, v.17, n.2, p.224-230, 2007.

HARMON, R. J.; EBERHART, R.J.; JASPER, D.E.; LANGLOIS, B.E.; WILSON, R.A Microbiological procedures for 
the diagnosis of bovine udder infection. Arlington: National Mastitis Council, 1990. 34p.

MATOS, F.J.A.; OLIVEIRA, F. Lippia sidoides Cham. farmacognosia, química e farmacologia. Revista Brasileira de Farmácia, v.79, p.84-87, 1998.

NADER FILHO, A.; FERREIRA, L.M.; AMARAL, L.A. do; ROSSI JUNIOR, O.D.; OLIVEIRA, R.P. Sensibilidade antimicrobiana dos Staphylococcus aureus isolados no leite de vacas com mastite. Arquivos do Instituto Biológico, São Paulo, v.74, n.1, p.1-4, 2007.

NUNES, G.P.; SILVA, M.F.; RESENDE, U.M.; SIQUEIRA, J.M. Plantas medicinais comercializadas por raizeiros no Centro de Campo Grande, Mato Grosso do Sul. Revista Brasileira de Farmacognosia, v.13, p.2, p.83-92, 2003.

OLIVEIRA, C.C. de; SIQUEIRA, J.M. de; REZENDE, U.M. Antibacterial Activity of Rhizomas from Cochlospermum regium: Preliminary results. Fitoterapia, v.67, n.2, p.176-177, 1996.

OLIVEIRA, F.P. de; LIMA, E. O.; SIQUEIRA JÚNIOR, J.P. de; SOUZA, E.L. de; SANTOS, B.H.C.; BARRETO, H.M. Effectiveness of Lippia sidoides Cham. (Verbenaceae) essential oil in inhibiting the growth of Staphylococcus aureus strains isolated from clinical material. Revista Brasileira de Farmacologia, v.16, n.4, p.510-516, 2006.

RANGEL, D.; GARCIA, I.; VELASCO, J.; BUITRAGO, D.; VELAZCO, E. Actividad antimicrobiana de los extractos etanólico, acetónico y acuoso de Baccharis nitida. Revista de la Faculdad de Farmacia, v.42, p.35-46, 2001.

RIOS, J.L.; RECIO, M.C. Medicinal plants and antimicrobial activity. Journal of Ethnopharmacology, v.100, n.1/2, p.80-84, 2005.

RODRIGUES, V.E.G.; CARVALHO, D.A. Levantamento etnobotânico de plantas medicinais no domínio do Cerrado na região do Alto Rio Grande - Minas Gerais Ciência e Agrotecnologia, v.25, n.1, p.102-123, 2001.

RODRIGUES, L.A.; CARVALHO, D.A. de; GOMES, L.J.; BOTREL, R.T. Espécies vegetais nativas usadas pela população local em Luminárias, MG. Boletim Agropecuário, n.52, p. 1-34, 2002.

SÁ, M.E.P.; CUNHA, M.S.R.S.; ELIAS, A.O.; VICTÓRIA, C.; LANGONI, H. Importância do Staphylococcus aureus nas mastites subclínicas: pesquisa de enterotoxinas e toxina do choque tóxico, e a relação com a contagem de células somáticas. Brazilian Journal of Veterinary Research and Animal Science, v.41, n.5, p.321-326, 2004.
SILVA, A.A. da; SOUSA, J.P.B.; SOARES, S.; FURTADO, N.A.J.C.; SILVA, M.L.A.; CUNHA, W.R.; GREGÓIO, L.E.; NANAYAKKARAC, D.N.P.; BASTOS, J.K. Antimicrobial Activity of the Extract and Isolated Compounds from Baccharis dracunculifolia D. C. (Asteraceae) Zeitschrift für Naturforschung, v.63, p.40-46, 2008.

SILVA FILHO, A.A.; SOUSA, J.P.B.; SOARES, S.; FURTADO, N.A.J.C.; SILVA, M.L.A.; CUNHA, W.R.; GREGÓRIO, L.E.; NANAYAKKARAC, D.N.P.; BASTOS, J.K. Antimicrobial activity of the extract and isolated compounds from Baccharis dracunculifolia D. C. (Asteraceae). Zeitschrift für Naturforschung, v.63, p.40-46, 2008.

SHER, A. Antimicrobial activity of natural products from medicinal plants. Gomal Journal of Medical Sciences, v.7, n.1, p.72-79, 2009.

SMITH-PALMER, A.; STEWART, J.; FYFE, L. Antimicrobial properties of plant essential oils and essences against very important food-borne pathogens. Letters in Applied Microbiology, v.26, 118-122, 1998.

SOUZA, L.K.H.; OLIVEIRA, C.M.A. de; FERRI, P.H.; SANTOS, S.C.; OLIVEIRA JUNIOR, J.G. de; MIRANDA, A.T.B.; LIÃO, L.M.; SILVA, M.R.R. Antifungal properties of Brazilian cerrado plants. Brazilian Journal of Microbiology, v.33, n.3, p.247-249, 2002.

SOUZA, G.N.; BRITO, J.R.F.; MOREIRA, E.C. BRITO, M.A.V.P.; BASTOS, R.R. Fatores associados à alta contagem de células somáticas do leite do tanque em rebanhos leiteiros da Zona da Mata de Minas Gerais. Arquivo Brasileiro de Medicina Veterinária e Zootecnia, v.57, p.251260, 2005. Suplemento 2.

SOUZA, C.D.; FELFILI, J.M. Uso de plantas medicinais na região de Alto Paraíso de Goiás, GO, Brasil Acta Botanica Brasilica, v.20, n.1, p.135-142, 2006.

TRESVENZOL, L.M.; PAULA, J.R.; RICARDO, A.F.; FERREIRA, H.D.; ZATTA, D.T. estudo sobre o comércio informal de plantas medicinais em Goiânia e cidades vizinhas Revista Eletrônica de Farmácia, v.3, n.1, p.23-28, 2006.

ZAFALON, L.F.; NADER FILHO, A.; OLIVEIRA, J.V.; RESENDE, F.D. Mastite subclínica causada por Staphylococcus aureus: custo-benefício da antibioticoterapia de vacas em lactação. Arquivo Brasileiro de Medicina Veterinária e Zootecnia, v.59, n.3, p.577-585, 2007.

ZECCONI, A.; HAHN, G. Staphylococcus aureus in raw milk and human health risk. IDF Bulletin, v.345, p.15-18, 2000.

Recebido em 11/5/09

Aceito em 5/8/10 